\title{
FILOSOFÍA COMO CIENCIA CRÍTICA
}

ERICH DANIEL LUNA

Pontificia Universidad Católica del Perú

El presente texto busca desarrollar y explicitar el concepto de filosofía que Martin Heidegger tenía desde la segunda mitad de la década de 1920, es decir, en los años que giran en torno a Ser y tiempo. Se toman como ejes los cursos dictados en esos años en la Universidad de Marburgo. La distinción entre ciencias positivas y ciencia crítica, así como la distinción entre filosofía científica y filosofía como concepción del mundo, tendrán por objetivo precisar qué es lo propio del quehacer filosófico: la diferencia ontológica. Tematizar el ser es lo propio de la filosofía para Heidegger, lo cual implica considerar que la filosofía en sentido pleno y eminente es ontología. Su relación con el ente no es positiva, pues se da en función al problema del sentido del ser. Todo ello nos permitirá tener una mejor comprensión de lo que Heidegger entendía por quehacer filosófico (ontología fenomenológica) y poder, así, estar en una mejor posición para comprender aspectos fundamentales del proyecto de la ontología fundamental desarrollado por Heidegger en Ser y tiempo.

Palabras clave:

Martin Heidegger, fenomenología, ontología fundamental, diferencia ontológica, ciencia crítica 
"Si la filosofía es la ciencia del ser, entonces se sigue como cuestión inicial, final y fundamental de la filosofía: ¿Qué significa ser?"

Martin Heidegger

En esta breve ponencia me ocuparé de la concepción que Martin Heidegger tiene acerca del quehacer filosófico en los años que giran en torno a la elaboración y publicación de Ser y tiempo' (1926-1927). Si es que SZ es una de las obras filosóficas fundamentales del siglo pasado, me parece imperativo esclarecer la manera en que Heidegger entiende, en dicho texto, lo que constituye la tarea del filósofo, así como el discutir acerca de las posibles consecuencias que parecieran seguirse de esta determinada visión de la filosofía.

Para esbozar las ideas fundamentales de este tema me remitiré, en lo esencial, a dos cursos que Heidegger dictó en los años cercanos a la publicación de $S Z$. El primero de ellos es Conceptos fundamentales de filósofía antigua² (1926), un curso de carácter introductorio muy importante, ya que Heidegger lo dictó mientras redactaba la segunda sección de SZ. El segundo curso en el que me basaré tiene por título Los problemas fundamentales de la fenomenología ${ }^{3}(1927)$, éste es el curso que Heidegger dictó después de haber publicado $S Z$ y que,

1 Heidegger, Martin, Sery tiempo, traducción de José Eduardo Rivera, Santiago de Chile: Editorial Universitaria, 1997. De ahora en adelante SZ.

2 Heidegger, Martin, Basic Concepts of Ancient Philosophy, translated by Richard Rojcewicz, Bloomington: Indiana University Press, 2008. Curso de Marburgo del semestre de verano de 1926. De ahora en adelante Conceptos fundamentales.

3 Heidegger, Martin, Los problemas fundamentales de la fenomenología, traducción de Juan José García Norro, Madrid: Trotta, 2000. Curso de Marburgo del semestre de verano de 1927. De ahora en adelante Problemas fundamentales. 
años más tarde, llegó a considerar como la tercera sección nunca publicada de dicha obra ${ }^{4}$.

El trabajo de divide en tres partes. En la primera abordaré la contraposición entre "ciencias positivas" y "ciencia crítica", esbozada en la introducción al primer curso mencionado, con el fin de mostrar ciertos rasgos esenciales del quehacer filosófico. En la segunda sección, a modo de segunda navegación, partiré de la contraposición entre "filosofía científica" y "visión del mundo" (Weltanschauung), una polémica distinción y oposición muy discutida en esta época. Dicha polémica nos interesa porque aborda el problema de lo que constituye como tal a la tarea de la filosofía y nos muestra la posición sostenida por Heidegger. Ambas contraposiciones nos permiten presentar una caracterización más precisa de la filosofía en las determinaciones que conciernen al tipo de campo temático que ella tendría, así como del que quedaría fuera, es decir, saber de qué, y con qué, trata la filosofía. Como puede ir viéndose, se trata de una pugna de tipo demarcatoria. Finalmente, en la tercera y última parte, plantearé de manera resumida la concepción de la filosofía que parece seguirse y las implicancias que parece traer consigo.

\section{§ 1. Ciencias positivas y ciencia crítica}

Hay ciertas opiniones comunes acerca de la filosofía de las que Heidegger parte para llegar luego a lo que propiamente $y$, en un sentido eminente, es la filosofía. La que me parece esencial para el tema que me interesa, es la afirmación (de sentido común) de que la filosofía trata de "preguntas universales", preguntas que pueden interesar a toda persona. Para llegar a esta conclusión lo que se hace, según Heidegger, es partir del prejuicio de que si la filosofía es algo "universal", entonces debe de ser también algo "universalmente" accesible y entendible. La filosofía no necesitaría de un método especial, sino

\footnotetext{
4 En la Introducción de los traductores Parvis Emad y Kenneth May al curso Interpretación fenomenológica de la Crítica de la razón pura de Kant, dictado en semestre de invierno 1927/1928, se cita la correspondencia entre Heidegger y Jaspers para mostrar que fue, principalmente, la opinión de Jaspers sobre la tercera sección de SZ lo que hizo que Heidegger desistiera de publicarla. Jaspers consideraba que era ininteligible. Cf. Heidegger, Martin, Phenomenological Interpretation of Kant's Critique of Pure Reason, Bloomington: Indiana University Press, 1997, pp. xi-xxi.
} 
fundamentalmente de "sentido común". Lo que se concluye de esta opinión común es que cualquier persona lúcida podría entender a la filosofía y, además, podría decir algo acerca de ella ${ }^{5}$.

La situación que plantea Heidegger para ejemplificar esta opinión común ilustra bastante bien como es que suele entenderse a la filosofía, en cuanto algo "universal". Imaginemos que un filólogo clásico va a una conferencia acerca de "teoría de funciones". Si es que entra, escucha la charla y no entiende absolutamente nada, entonces todo le parece que está en orden. $Y$ si es que un químico va a una charla acerca de filología hindú y no entiende nada, también siente que las cosas están bien. Pero si ambos, junto a todos sus demás colegas de distintas disciplinas y departamentos, van a una conferencia sobre filosofía y no entienden absolutamente nada, entonces sienten que algo "anda mal", que algo "no está en orden", ya que, según el prejuicio ya presentado anteriormente, la filosofía debería de ser algo universalmente accesible a todos. En pocas palabras, parece ser que el error radica en pensar que lo que nos convoca universalmente a todos, la filosofía, tiene que necesariamente ser algo fácilmente entendible y asequible por todos ${ }^{6}$.

Si ahondamos en las consecuencias de este prejuicio, veremos que éste se concretizaría y manifestaría en el mundo académico a través de "cursos generales" o "introductorios" de filosofía. Lo que buscarían estos cursos sería enseñar "visiones del mundo" o "cultura general". La historia de la filosofía devendría, así, la historia de múltiples anécdotas, datos y maneras de ver el mundo. De esta manera, para Heidegger, la que en sus orígenes era la ciencia más fundamental y radical quedaría relegada a ser un mero asunto de cultura general y erudición acerca de datos y ocurrencias.

Si partimos de la opinión común comentada y la rechazamos como errada, la conclusión inmediata sería quizá pensar, entonces, que la filosofía no es tan universal como parece, que quizá sería más bien una ciencia específica como las otras ciencias, con su propio campo de objetos y con su propio método. Pero lo más importante no es eso, sino el que la filosofía quedaría restringida

Cf. Heidegger, Martin, Conceptos fundamentales, p. 2.

${ }^{6}$ Cf. ibid. 
para un grupo reducido de personas, como ocurre con las demás ciencias, debido a la necesaria formación "técnica" y especializada que se requeriría. Vemos aquí también erudición, pero fuertemente particular y especializada, en oposición al primer tipo de erudición, que era más de tipo general'7.

Heidegger no está de acuerdo tampoco con esta opinión. Frente a negar la primera opinión de manera radical, lo que quiere Heidegger es ahondar en lo que significa realmente esta "universalidad" de la filosofía que se vio expresada de una manera poco clara en el prejuicio cotidiano ya mencionado. Además de esto, también va a buscar en qué sentido, si es que lo hay, es que puede llegar a entenderse a la filosofía como una ciencia, aunque no sea, ni pueda ser, propiamente una "especialidad" al modo de las demás ciencias.

El punto de partida que vamos a tomar a continuación como camino e hilo conductor, para clarificar esto, será el de las ciencias con las que cotidianamente contamos, y con las que comúnmente nos ocupamos. A partir de ellas es que se tratará de determinar a la filosofía. Empezamos entonces, constatando una serie de disciplinas científicas en nuestro mundo cotidiano: matemáticas, física, historia, lingüística, filología ${ }^{8}$, etc. Lo interesante y esencial de estas ciencias es, para Heidegger, que no empiezan cuestionando qué es lo que son. Por ejemplo, el preguntarse qué son las matemáticas ellas mismas a sí mismas, o que la física se pregunte a sí misma qué es la física, etc. A lo mucho, lo que normalmente hacen es darnos una descripción esquemática y general que nos permita, rápidamente y de una vez, empezar a hacer ciencia. Heidegger considera que este rasgo es esencial y constitutivo para este tipo de disciplinas, lo cual, obviamente, no tiene un sentido peyorativo o despectivo.

Si le preguntáramos a un matemático que nos diga qué son las matemáticas, lo más probable es que nos muestre su trabajo científico, esto es, que empiece a hacer matemáticas para que veamos de qué se trata. Pero si quisiera hablar acerca de lo que constituye al objeto de la matemática, o a su método, entonces

\footnotetext{
7 Es importante no perder de vista que este primer curso al que hago referencia era de tipo introductorio, es decir, que no estaba dirigido a alumnos de la especialidad de filosofía. De ahí que lo que quiera hacer Heidegger con ellos sea todo menos eso que él llama, peyorativamente, "cultura general".

8 Cf. Heidegger, Martin, Conceptos fundamentales, p. 4.
} 
parece que no podría hablar de eso matemáticamente. Lo que parece ocurrir es que al intentar indagar en estas cuestiones, dejan de hacer matemáticas y, en cambio, empiezan a hacer algo distinto: empiezan a filosofar. Al hacer esta constatación, Heidegger hace una distinción entre lo que serán dos tipos de ciencias: ciencias positivas (lo que entendemos usualmente por ciencia) y ciencia crítica: la filosofía.

En el primer grupo se encuentran todas las disciplinas que comúnmente consideramos ciencias. Lo que las unifica es el hecho de que parten ya siempre dando por supuesto (ponere, positum) su objeto. Su objeto ya "yace ahí", es un positum, algo puesto o dado. Como ejemplo diríamos que los números "ya están ahí”, también la naturaleza, el lenguaje, etc. Este tener previamente puesto su objeto hace que las llamemos ciencias positivas. Esto puesto que ya "yace ahí" son lo que Heidegger llama entes. Todo lo que estas ciencias pueden descubrir, tratar y tematizar son entes. Podemos decir pues, que las ciencias positivas son las ciencias que se ocupan de los entes?.

No debemos pensar sin embargo, que ente es algo exclusivo de la ciencia positiva, sino al revés: la ciencia positiva es algo exclusivo de los entes. En SZ, Heidegger deja en claro que "ente" es un término mucho más amplio, cuasi "omniabarcante": "Pero llamamos 'ente' a muchas cosas y en diversos sentidos. Ente es todo aquello de lo que hablamos, lo que mentamos, aquello con respecto a lo cual nos comportamos de ésta o aquella manera; ente es también lo que nosotros mismos somos, y el modo como lo somos" ${ }^{10}$. Constantemente pues, nuestra existencia está inmersa en medio de los entes, se ocupa de los entes, está referida a los entes. Incluso nosotros mismos somos entes. Las ciencias positivas son una ocupación específica que hacemos nosotros con los entes, una tematización particular acerca de los diversos entes: números, naturaleza, lenguaje, vida, Dios, etc.

Lo que tiene que desprenderse de aquí, y que es fundamental para entender qué es la filosofía para Heidegger, es que si la filosofía no es una ciencia positiva, eso tiene que significar que lo que ella tematiza, científicamente, no 
son entes. Lo que debe aclararse a continuación, entonces, es qué es lo que tematiza. Para llegar a ese propósito partiremos explicando en qué sentido debe entenderse que la filosofía es la ciencia "crítica".

Ciencia crítica no significa para Heidegger que la filosofía sea "rigurosa", "metodológicamente correcta", o "seria". Esos criterios son los que usualmente asumimos para cualquier quehacer que se quiera científico, y no son únicamente propiedad de la filosofía. En todo caso, tanto las ciencias positivas como la ciencia crítica tienen su propia manera de ser "rigurosas". Tampoco se está aludiendo aquí a un quehacer de tipo kantiano (p.e. "proyecto crítico") o marxista (p.e. "teoría crítica"). Heidegger nos remite al origen griego de la palabra: krinein que significa "delimitar", "diferenciar". Pero también puede replicarse que continuamente las ciencias positivas diferencian y delimitan sus objetos de estudio. Por ejemplo, la matemática debe diferenciar los números de la naturaleza, en cuanto posibles objetos de ocupación científica, así como la física debe diferenciar la naturaleza de los demás entes y así con todas y cada una de las ciencias positivas. Si la filosofía puede llegar a llamarse - llegar a ser considerada "ciencia crítica" es porque debe de ser "crítica" en un sentido eminente.

Lo que podemos decir acerca de los entes, sin diferenciarlos entre ellos, es decir que son. En el ejemplo anterior, podemos decir que tanto los números, como la naturaleza son, a pesar de diferenciarlos. A pesar de que incluso su manera de ser es distinta, comparten algo así como el ser. Y es que, si bien los entes pueden ser muy distintos entre sí, lo cierto es que lo que comparten es el hecho de que son. En pocas palabras, el ser entes es algo que comparten todos los entes. Entonces, si tomamos la totalidad de lo ente, lo que puede diferenciarse del ente, en un sentido eminente y fundamental, es su ser. Esta diferenciación no es pues, entre un ente y otro, sino más bien, entre los entes y el ser, entre cada ente y su ser, entre la totalidad del ente en general y el ser en general. Diferenciar el ser del ente es pues, la tarea diferenciadora eminente, la tarea verdaderamente crítica propia de la ciencia crítica: la filosofía.

Hay que agregar a esto un factum esencial del que Heidegger parte. Habíamos empezado la reflexión sobre la filosofía, en esta primera parte, a partir de la constatación cotidiana de las ciencias positivas y, a través de ellas, llegamos a 
lo que es la filosofía. Pero no debemos perder de vista, en ningún momento, que antes de hacer ciencia, ya estamos tratando con los entes, aunque no de manera científica. Esta ocupación o tratamiento precientífico que tenemos con el ente es mucho más originario que el tratamiento científico por el que hemos partido para llegar a la filosofía. Al ocuparnos de ellos cotidianamente, podemos constatar como un fenómeno positivo, el hecho de que tenemos una comprensión precientífica del ser. Heidegger llamará a la comprensión del ser que el ser humano tiene, una comprensión preontológica. Esto significa que no tenemos una comprensión explícita, totalmente clara, o acabada del ser.

Sin embargo, a pesar de que el ser de arranque parece estar "oculto" o permanecer "oscuro" para nosotros, siempre es de alguna manera comprendido. Esta comprensión es previa o fundante para la experiencia y comprensión que podamos llegar a tener de los entes. Esto significa que si bien las ciencias positivas no tematizan acerca del ser del ente, eso no implica que no tengan cierta comprensión de éste, aunque dicha comprensión no esté nada tematizada o explicitada.

Esto vale también para la experiencia cotidiana de la existencia humana y de la manera más fundamental. Todos comprendemos cuando decimos "EI simposio es hoy", "La ponencia es de Daniel”, "El vaso de agua está sobre la mesa”, etc. Todos comprendemos el ser en estas expresiones, comprendemos los diversos modos de ser de los diversos entes mentados en los ejemplos, aunque quizá no podamos responder de manera clara qué es el ser. Tenemos una cierta comprensión no temática, y no una formulación conceptual acerca de lo que propiamente es del ser. Este factum de una comprensión implícita del ser que debe ser explicitada es la base sobre la que se plantea la tarea de SZ, a partir de la pregunta, justamente, por el sentido del ser en general. Responder temática y conceptualmente a dicha cuestión es la tarea central de la empresa heideggeriana de estos años. Pero así como para investigar a los entes, las ciencias positivas tienen métodos específicos, pareciera que la ciencia crítica necesita de métodos propios para su tarea: la de desocultar el ser del ente.

Lo que entonces la filosofía debe de "criticar" (entendido como diferenciar) no son los resultados de las ciencias positivas, sino el ser con respecto del 
ente. Este es para Heidegger el sentido propio de la inicialmente llamada "universalidad" de la filosofía. Es universal porque lo que tiene que tematizar es el ser, algo universalmente presente en todo ente, ya que todo ente es. Pero a pesar de tener esta universalidad, no puede considerarse una ciencia positiva porque el ser nunca se nos da de manera explícita de antemano, sino que debemos buscar descubrirlo y desocultarlo".

\section{§ 2. Filosofía científica o visión del mundo (Weltanschauung)}

Heidegger, en la Introducción a Los problemas fundamentales, empieza hacien-

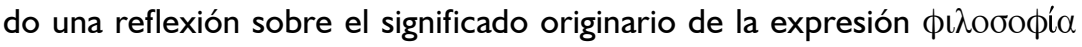
Dice que en sus inicios, este término era sinónimo de "ciencia en general”, y que es a partir de ella que surgen "filosofías particulares", es decir, ciencias particulares. La filosofía es pues, la "ciencia por antonomasia", la ciencia "absoluta", "primera y superior": la madre y fundamento de todo otro quehacer científico. Si asumimos esta definición de la filosofía, entonces la expresión "filosofía científica" resultará ser un pleonasmo, "Basta con decir simplemente filosofía. Ésta ya implica ciencia por antonomasia”'2.

¿Por qué entonces la expresión "filosofía científica"? Porque desde que existe esta concepción de la filosofía, se encuentra una que, para Heidegger, es radicalmente opuesta. Esta otra posición considera que la filosofía no es "filosofía científica", ya que lo fundamental de la filosofía no es ser una ciencia teórica, sino más bien, el ser una sabiduría práctica del mundo en el que los seres humanos viven. Esto significaría que "la filosofía tiene que dirigir, de forma práctica, la comprensión de las cosas y de sus relaciones y las tomas de posición respecto de ellas y ha de regular y gobernar la interpretación del Dasein y de su sentido"'3. En pocas palabras, "la filosofía ha de proporcionar

"Este método será el método fenomenológico, que para Heidegger constituye el método filosófico por antonomasia, la manera científica de hacer filosofía: "Nosotros afirmamos que la fenomenología no es una ciencia filosófica entre otras, tampoco es la propedéutica de las demás, sino que la expresión 'fenomenología' es la denominación del método de la filosofía científica en general” (Problemas fundamentales, § I, p. 27).

12 Ibid., p. 28.

13 lbid. 
una concepción del mundo"14. La visión del mundo es, además de muchas cosas, una interpretación acerca del sentido y fin del Dasein (de la existencia humana), que estaría dada y configurada de una manera puramente histórica y cultural ${ }^{15}$.

A la filosofía entendida como concepción del mundo le compete abordar ciertas "preguntas últimas", lo que usualmente entenderíamos por los genuinos problemas filosóficos ${ }^{16}$, con el fin de poderles dar respuesta. Esta manera de entender a la filosofía también se consideraría como "científica", ya que debería apoyarse en los resultados científicos de las demás ciencias para poder elaborar una concepción filosófica del mundo.

Pero lo importante que debe de señalarse es que la "visión del mundo" surge del Dasein fáctico y de sus posibilidades fácticas. La Weltanschauung es positi$v a^{17}$, ya que pone al ente y mantiene una relación con él. Es por esta relación positiva que la Weltanschauung mantiene con el ente que es, con el mundo que es y con el Dasein que es, "por lo que no cabe que sea tarea de la filosofía la elaboración de una concepción del mundo; lo que no excluye, sino que incluye, que la filosofía misma sea una señalada forma originara de concepción del mundo. La filosofía puede -y quizás debe- mostrar, entre otras muchas cosas, que a la naturaleza esencial del Dasein pertenece algo así como una concepción del mundo. La filosofía puede y debe delimitar lo que constituye en general la estructura de una concepción del mundo". Pero nunca puede desarrollar y poner esta o aquella determinada concepción del mundo ${ }^{18}$.

Para que Heidegger pueda concluir que a la filosofía no le compete el proveer una concepción del mundo, hay que rechazar una tesis fundamental: que la filosofía no tiene una relación positiva con el ente. La pregunta que surge de inmediato es si es que puede realmente haber algo con lo que la filosofía

\footnotetext{
14 Ibid.

${ }^{15}$ Hay una casi infinitud de variables tales como raza, pueblo, desarrollo científico, económico, etc.

${ }^{16}$ Por ejemplo, preguntas acerca del hombre, del mundo, de la naturaleza, del alma, de la libertad, de la historia, de Dios. Son pues, las "preguntas universales" que fueron mencionadas en la primera parte de la ponencia como lo propiamente "universal" que tiene la filosofía.

17 Recuérdese el sentido de positivo propio de la ciencia positiva, y su vinculación con el ente, desarrollado en la primera sección de la ponencia.

${ }^{18}$ Heidegger, Martin, Problemas fundamentales, pp. 34-35. Los subrayados son míos.
} 
tuviera que ver que no sea el ente. "Dios", "naturaleza”, "hombre", "historia", etc., pueden abarcar la totalidad de lo que nos referimos con la expresión "ente". Y por muy diferentes que puedan ser estas "regiones de lo ente", lo cierto es que comparten algo fundamental: el hecho que son. En pocas palabras, entender la filosofía como una concepción del mundo es pensar en una relación positiva con el ente. Se trata de una ocupación óntica. La filosofía, si quiere ser el quehacer ontológico, debe ocuparse del ser y ello es algo que implica una relación negativa para con el ente.

A esto hay que añadir, una vez más, el factum del que parte el análisis heideggeriano: "en definitiva, hay algo que tiene que haber para que se nos haga accesible el ente como ente y nos podamos comportar respecto de él, algo que, sin duda, no es, pero que debe haber para experimentar y comprender algo como el ente. Somos capaces de comprender al ente como tal sólo si entendemos algo como el ser"|9. Lo que esto quiere decir es que para que el ente se nos pueda dar y podamos relacionarnos de una manera positiva con él, debemos de tener previamente una comprensión del ser que posibilite esta relación. Pero no hay que olvidar que esto "no quiere decir, claro está, que tengamos que tener antes un concepto explícito de ser para experimentar teórica o prácticamente el ente. Debemos comprender el ser, ser que no puede ser ya denominado ente, ser que no puede aparecer como un ente entre los demás entes, pero que, sin embargo, debe darse y de hecho se da en la comprensión del ser" ${ }^{20}$. Heidegger llama esta diferencia, la diferencia entre el ser y el ente, diferencia ontológica. A grandes rasgos, porque no podemos ahondar en estas expresiones, "óntico" será la expresión que refiera a lo que tiene que ver con el ente, mientras que "ontológico" será la expresión que se referirá a lo que tenga que ver con el ser del ente.

Es a partir de aquí que Heidegger explícitamente sostiene que "el ser es el verdadero y único tema de la filosofía" 21 . La filosofía es la ciencia del ser, es decir, ontología. En paralelo a la diferencia ontológica es que Heidegger distingue a la filosofía de los demás quehaceres: "La filosofía es la interpretación teóricoconceptual del ser, de su estructura y de sus posibilidades. Es ontológica. Por

\footnotetext{
19 Ibid., p. 35.

20 lbid., p. 36.

21 Ibid.
} 
el contrario, la concepción del mundo es un conocimiento ponente del ente y una toma de postura ponente del ente, no es ontológica, sino óntica. La elaboración de la concepción del mundo cae fuera del círculo de tareas de la filosofía, no porque la filosofía esté en una situación imperfecta y no esté todavía en disposición suficiente para dar una respuesta unánime y universalmente convincente a las cuestiones de una concepción del mundo, sino que la elaboración de la concepción del mundo cae fuera del círculo de tareas de la filosofía porque ésta no se refiere fundamentalmente al ente"22.

De lo anterior Heidegger concluye que no puede haber una real contraposición y disyunción entre "filosofía científica" y "filosofía como visión del mundo" porque a la filosofía no le compete, ni puede llegar a competerle, el proveer una concepción del mundo. La expresión "filosofía de la concepción del mundo" es, desde esta perspectiva, algo tan absurdo como hablar de un "círculo cuadrado", o de un "hierro de madera"23. El otro término, "filosofía científica”, también queda disuelto, ya que la filosofía para Heidegger es científica ${ }^{24}$ en su concepto, por definición. Con lo cual no hay disyunción entre, 0 filosofía como ciencia, o filosofía como concepción del mundo. Únicamente hay filosofía, entendida como ontología científica y fenomenológica ${ }^{25}$.

"La filosofía es ciencia del ser. Por filosofía entenderemos de ahora en adelante 'filosofía científica' y nada más. De acuerdo con esto, todas las ciencias no filosóficas tienen como meta el ente, y ciertamente, de tal manera, que este se les presenta de antemano siempre como ente. Lo presuponen, es para ellas un positum. Toda proposición de las ciencias no filosóficas, también las de la matemática, son proposiciones positivas. Por ello decimos que todas las ciencias no filosóficas, a diferencia de la filosofía, son ciencias positivas. Las ciencias positivas tratan del ente, esto es, en cada caso de una determinada esfera, por ejemplo, de la naturaleza"26.

\footnotetext{
22 Ibid., pp. 36-37.

${ }^{23}$ Esta expresión es la que Heidegger utiliza para mostrar el contrasentido de una "filosofía cristiana" en el curso Introducción a la metafísica, de 1935.

${ }^{24}$ Pero es una cientificidad que debe entenderse en un sentido más amplio y originario que el de la ciencia moderna positiva.

${ }^{25}$ Las referencias al método fenomenológico como el método propio de la filosofía, como la cita de la nota II, son abundantes y profundas. De ahí que se hallen fuera de la exposición presente, ya que su problemática (que es fundamental) excede los límites de la ponencia presentada. 


\section{§ 3. Cuestiones finales}

Hemos visto que, a partir de la diferencia ontológica, Heidegger designa dos quehaceres. El primero es un quehacer óntico, que se refiere a los entes y que los asume como dados. Como quehaceres ónticos, Heidegger menciona a las ciencias positivas y a las "concepciones del mundo". El segundo es un quehacer ontológico que se refiere al ser del ente y que, asumido de manera radical, busca tematizar y conceptualizar el sentido del ser en general. Este quehacer es el de la ciencia ontológico-crítica: la filosofía, cuyo método propio es el fenomenológico.

El problema fundamental que parece presentarse es que a partir de la diferencia ontólogica, la filosofía devendría incapaz de abordar preguntas que tengan por campo las posibilidades ónticas del Dasein. Esto significaría que a la filosofía no le competería responder cuestiones como las clásicamente enumeradas por Kant: “¿Qué puedo conocer?”, “¿Qué debo hacer?”, “iQué me cabe esperar?"y "¿Qué es el hombre?"27. Todas estas preguntas interrogan por el ente y únicamente la ciencia positiva es el quehacer óntico que puede llegar a dar cuenta de estas preguntas.

Lo que haría el filósofo sería más bien describiry analizar fenomenológicamente los conceptos fundamentales de cada ciencia en relación a la comprensión de la cuál surgen las diversas regiones ontológicas. E incluso, esto sería hecho con vistas a una ontología fundamental, para poder abordar la pregunta acerca del sentido del ser en general.

¿Se tiene que seguir necesariamente una concepción de la filosofía de este tipo a partir de la llamada "diferencia ontológica"? ¿Debería, si es esto así, abandonarse esta diferencia? ¿Sería mejor que la pregunta por el sentido del ser "cayera en el olvido de nuevo" en beneficio de que el filósofo tenga por campo temático de su quehacer a los entes y a las posibilidades ónticas del Dasein?

${ }^{27}$ Quizá esta última pregunta podría ligarse a la filosofía, si se reformula como "¿Cómo es el Dasein y cuál es el sentido de ser?", aunque dicho cuestionamiento, si bien llevaría a la analítica del Dasein desarrollada en $S Z$, no dejaría de tener un carácter explícitamente provisional, ya que la verdadera pregunta es la pregunta por el sentido del ser en general. 